\title{
Improvement of handle grip using reverse engineering, CAE and Rapid Prototyping
}

\author{
Pavel Stoklasek ${ }^{1, a}$, Ales Mizera $^{1}$, Miroslav Manas ${ }^{1}$ and David Manas ${ }^{1}$ \\ ${ }^{1}$ Tomas Bata University in Zlin, nam. T.G. Masaryka 5555, 76001 Zlin, Czech Republic
}

\begin{abstract}
The overwhelming majority of manual operations is even nowadays performed by using manual hand tools. These tools can be divided into 2 groups - hand tools designed for general use or a single-purpose hand tools for special operations. Tool described in this paper is used in assembling operation in the completion of electric motor. During the design of the existing tools the requirements for a functional part of the tool (lifespan, inability to damage the engine installation) were fully considered, demands for ergonomic grip area, however, were not taken into account. Long-term use of incorrectly designed tool causes carpal tunnel syndrome, hand-arm vibration syndrome, diminished sensitivity or tingling in the fingers of workers. These difficulties can be reduced or entirely eliminated due to proper design of the grip of hand tool. Most authors focus on adjusting the grip for optimum ergonomics at individual types of grips (cylindrical, palmar, lateral, etc.). However, as already mentioned, there are tools for specific operations when the working area is limited by space or a specific type of load on the grip is needed. In some cases, it is often necessary to change the type of grip or combine different types of grips. This paper describes the design of an optimal grip of hand tool used for specific operation when assembling motors. Design of prototype mold and production of functional prototypes for ergonomics assessment directly in the workplace were realized. New design of handle should reduce the risk primarily of developing carpal tunnel in long-term use.
\end{abstract}

\section{Introduction}

Tool handles have been improving for thousands of years. People have tried to modify the tool handles for improving effectiveness of the work with them. Proper design of the handle is important for comfortable work. Companies producing tools often disregard the ergonomic requirements of individual consumers. Handles of these tools are often too small, stiff, sharp or misplaced. There are many different sizes of hands and every person is holding a tool according to habit.

Tools are often used differently than were designed, the contact between the hand and the tool handle is wrong or inaccurate. At first feeling improperly designed thickness, length and position of the handle can be detected. The functional and ergonomic requirements must be effectively interconnected when developing new hand tools. Grip should be designed with consideration to ergonomic which has a significant effect on muscle problems in the wrist. [1, 2]

Handle length should be at least 10 to $15 \mathrm{~cm}$ to cover the entire width of the palm. The diameter of the tool handle for maximum performance is for an adult male 30 - $45 \mathrm{~mm}$. The shape of the handle should have a cylindrical or spherical cross-section due to good contact with the hand. Most tools has a designed area for the thumb and the combined area for other fingers, which prevents unintentional twisting of the hand. The general rule is to eliminate sharp edges and elevated places in contact with the hand. Properly designed handle should transfer the best possible strength of hand into tool and also ensure the best possible safety while working. Elevations may be used on the edge of the handle to prevent slipping of the hand and accidental injuries. The smooth surface is used on the handles, along which the hand moves and rotates. Rough surface is used on some products purposely to fix the arm in correct place. These are only general recommendations - every new handle tool design must be individually adapted to the needs of the specific operation and comfort of the worker. [3-9]

\section{Experimental}

\subsection{Original tool}

The existing tool consists of two main parts - the handle and the working part. The handle is made of pertinax composite material made of paper impregnated with a plasticized phenol formaldehyde resin. The handle is made by combining machining, cutting and grinding. The working part is made of tool steel. Both parts are connected with two screws.

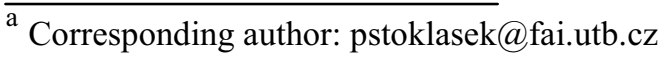




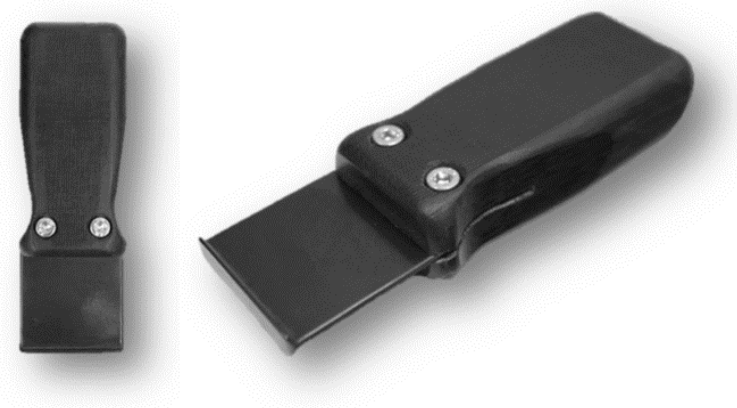

Figure 1. Original tool.

\subsection{Design of improved tool}

First, a handle shape of modeling clay was created on the working part of the tool. Two combined grip types (cylindrical and palmar) were chosen based on videoanalysis of work and workers comments. The handle was enlarged and anatomically shaped for a new type of grip. The handle enlarging had increased contact area in the palm. In comparison with the original tool, new design fully respects the general requirements for ergonomics.

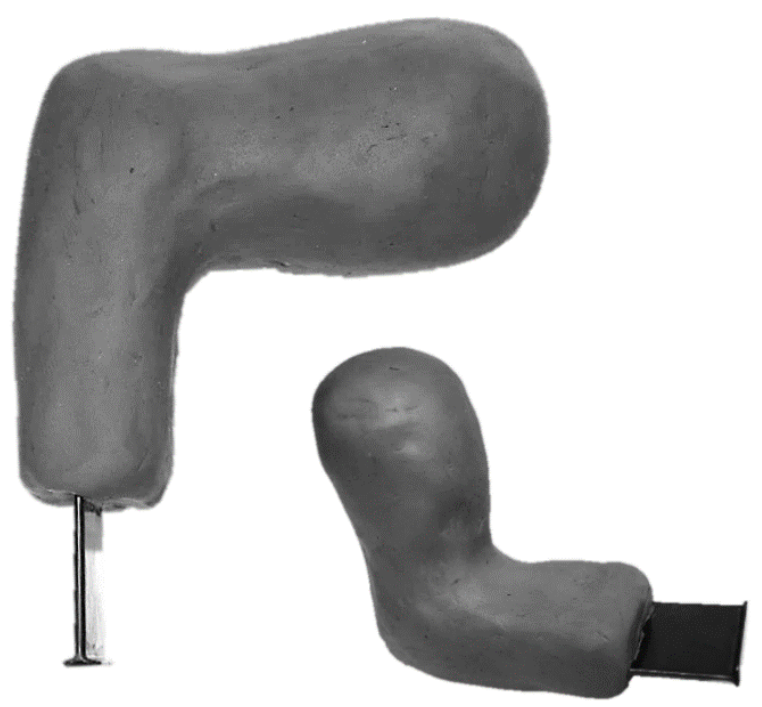

Figure 2. New design of handle tool.

Clay model was scanned by using a contactless 3D scanner ATOS II TripleScan 5M (GOM, Germany). The final model consisted of 16 scans ( 8 shots on each half of the model). The entire surface of the model was modified in the program GOM Professional (GOM, Germany) to eliminate minor irregularities and patch small holes. The data was then exported in STL format. The total scanning time was 7 minutes, the time of postprocessing operations was 10 minutes.

The surface of the model was smoothed in the program Geomagic Design X (3D Systems, USA). Based on surface analysis a plane of symmetry was created. This plane is also used as the parting plane of future mold. Due to left-handed and right-handed use of new tool it is necessary to have a symmetrical shape at this stage of design. One of halves of the model was removed and replaced by a mirror copy of the original half. The created model was again smoothed (especially in the area of parting plane) and using a standard reverse engineering steps converted to a volumetric 3D model. Total time of handle reverse engineering operations was 35 minutes.

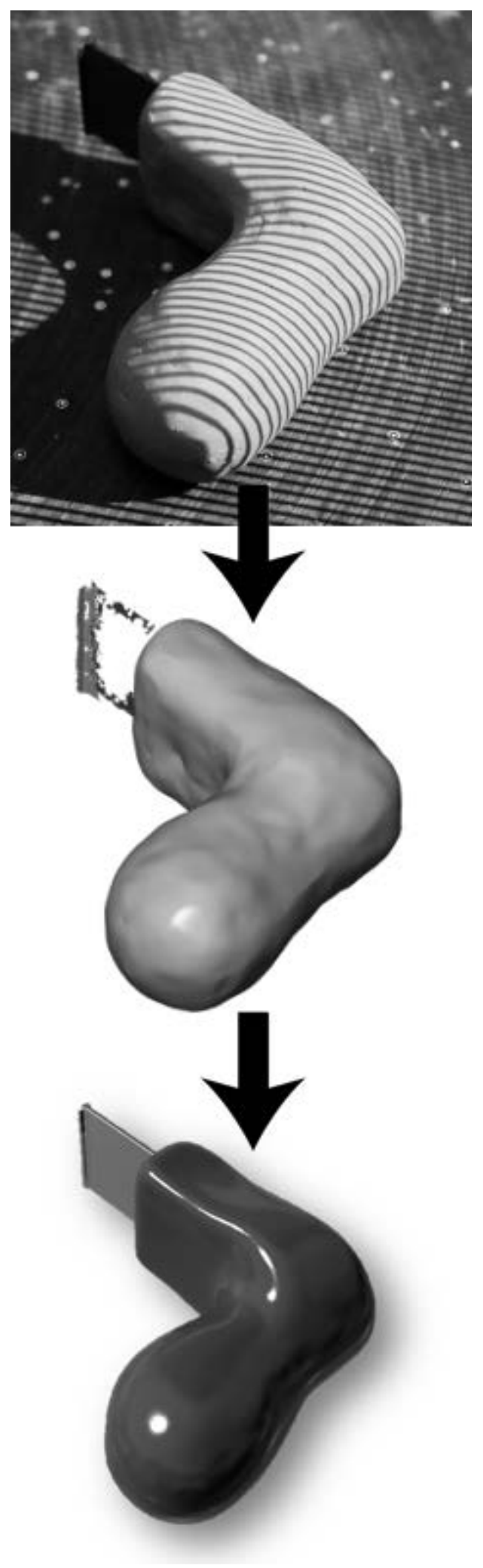

Figure 3. Workflow: 3D scanning - STL export - CAD model. 


\subsection{Mold design}

Mold was designed in Autodesk Inventor Professional 2016 (Autodesk, USA). The cavity was created by using Boolean difference model of the handle and block of mold. When designing mold it is necessary to specify both the position the gate and the position of the handle during the injection of polyurethane foam. The vents 4 must be in the highest position of the mold cavity. Figure 4 shows CAD design of injection mold of new handle tool where metal functional part 3 is molded into polyurethane grip element. Mold parts, particularly gate 1 and the leader pins 2 are for increasing resistance to abrasion and deformation made of metal. Mold fully complies with the demands on the technology of polyurethane injection. [10]

Total time of mold design was 3 hours.

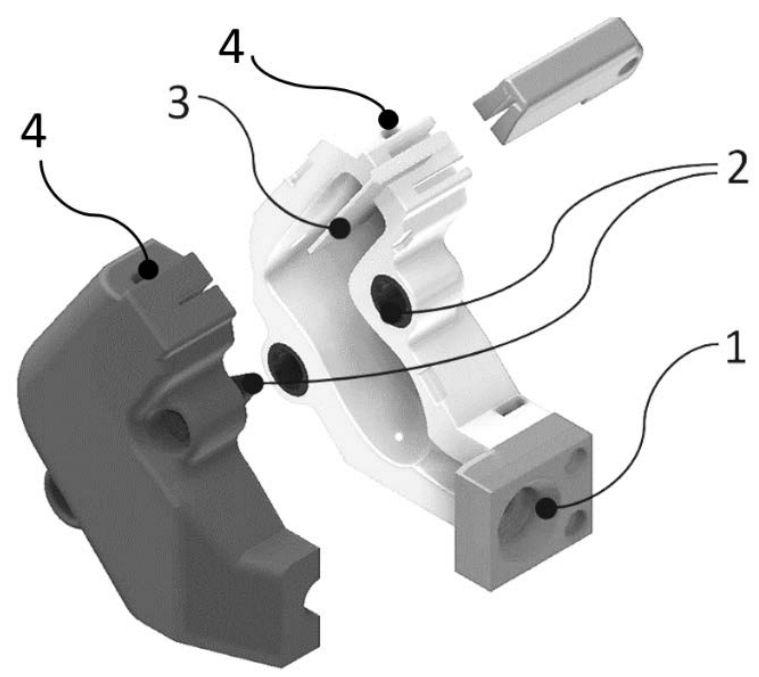

Figure 4. Prototype mold design.

Fortus 900mc (Stratasys, USA) was used for mold building. Due to sufficient temperature resistance ABS was used as a building material. Maximum temperature of injected PUR foam is not higher than $90^{\circ} \mathrm{C}$. The height of the print layer was $0.17 \mathrm{~mm}$. After printing the support material was chemically removed in ultrasonic cleaner. Total time of mold 3D printing and support removing was 20.5 hours (18 hours printing, 2.5 hours postprocessing operations).
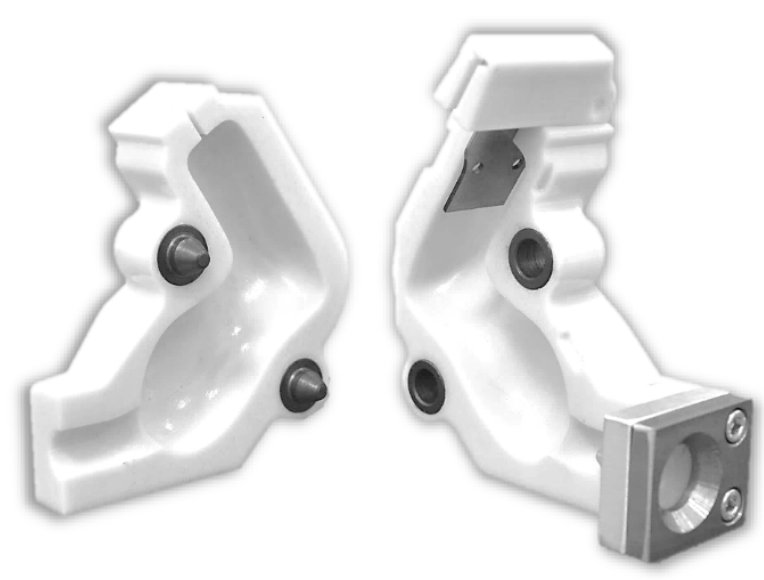

Figure 5. Completed mold.
Figure 5 shows the completed mold. All parts of mold were sandblasted and chemically smoothed in acetone vaporizer. After surface finishing the mold cavity was coated with thick layer of PUR foam separator which was soaked into material and filled micro-cavities and surface roughness. The separator was removed after 10 minutes and mold was dried. Before injecting of the polyurethane normal layer of separator was applied. Separation is used to removing injected part without difficulty. Total time of mold cavity postprocessing and mold completing took about 2.5 hours.
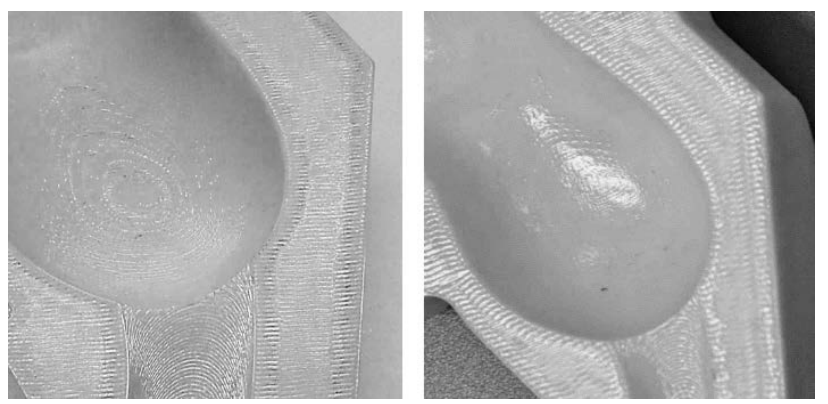

Figure 6. Surface comparison (before/after aceton smoothing).

Before the injection molding process it is necessary to heat the mold to $50^{\circ} \mathrm{C}$. The prepared mold was placed in an oven for 15 minutes. In case of repeated injection is not necessary to repeat this operation. Production cycle of one part is 7 minutes. After each removal of the part the separation the process must be repeated.

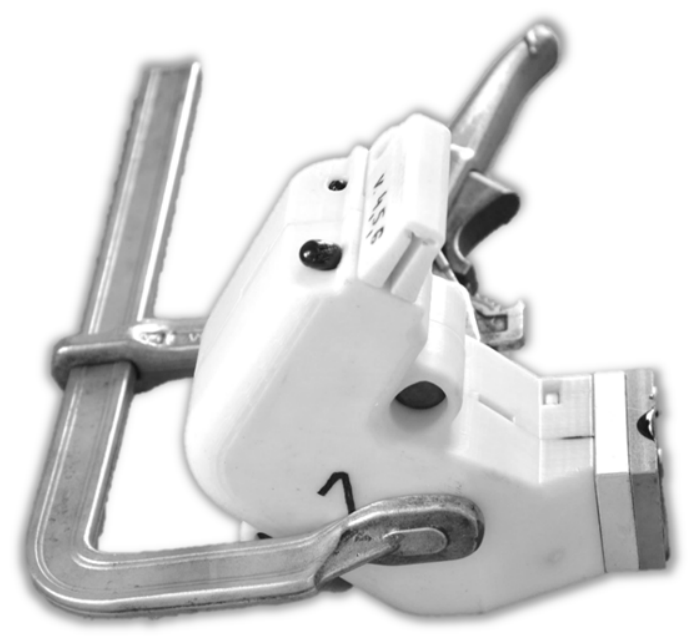

Figure 7. Mold after injection of PUR foam.

\section{Results and conclusion}

Combination of optical digitalization and rapid prototyping methods were used to minimize the manufacturing time of mold. These methods are applicable to the most of currently used manufacturing processes and can save significant amount of resources mainly in field of pre-production and early design processes. In this article, the methods were applied to 
specific problem of ergonomic and functional design of hand tool. New tool design is shown on the Figure 5. It was manufactured about 20 prototypes for ergonomics assessment directly in the workplace.

Main advantages of the new solution were observed on comfort of workers. According to the survey $74 \%$ of workers stated improvement of muscle load in hand area. Also manufacturing process of new tool is shorter and does not need any conventional milling operations which are not so productive as injection PUR molding.

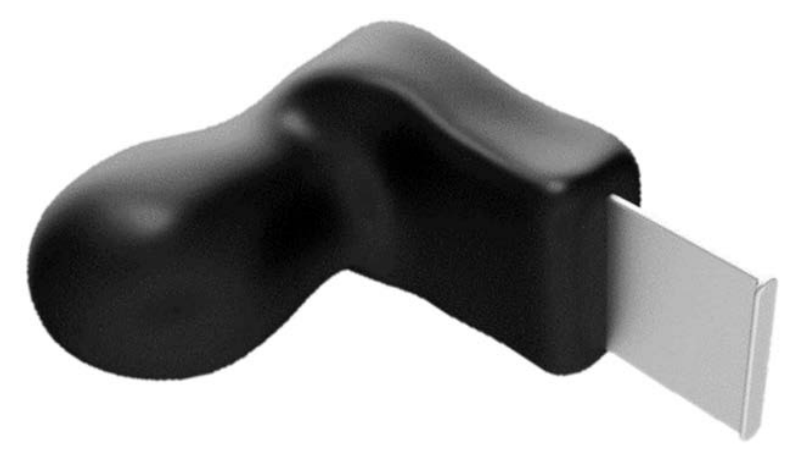

Figure 8. New tool.

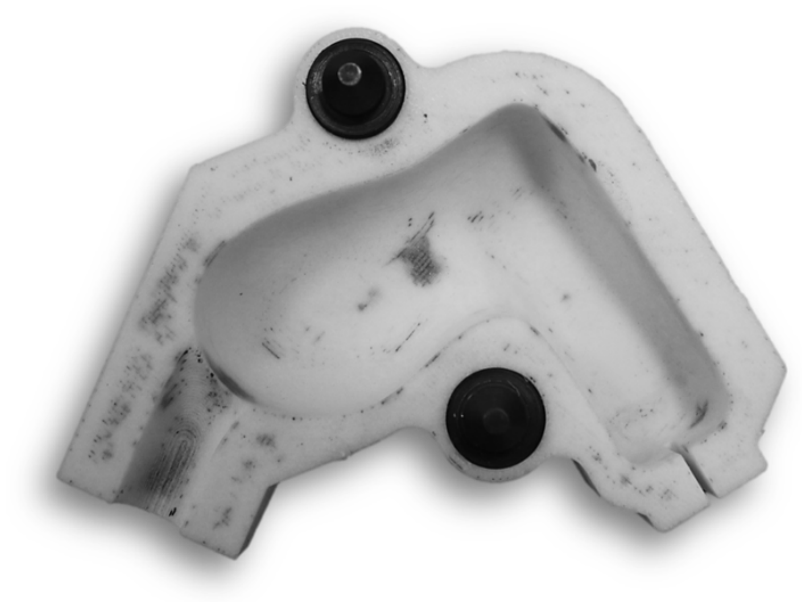

Figure 9. Mold cavity after injection of 20 parts.

Table 1. Time summary of all operations.

\begin{tabular}{|l|c|}
\hline \multicolumn{1}{|c|}{ Operation } & Time (h) \\
\hline 3D digitizing, postprocessing & 0,6 \\
\hline $\begin{array}{l}\text { polygonal data processing, reverse } \\
\text { engineering }\end{array}$ & 0,8 \\
\hline mold design & 3,0 \\
\hline 3D printing time, postprocessing & 20,5 \\
\hline mold completing & 2,5 \\
\hline production cycle & 0,1 \\
\hline
\end{tabular}

\begin{tabular}{|l|c|}
\hline TOTAL & 27,5 \\
\hline
\end{tabular}

\section{Acknowledgments}

This paper is supported by the internal grant of TBU in Zlin No. IGA/FT/2016/010 funded from the resources of specific university research and by the Ministry of Education, Youth and Sports of the Czech Republic within the National Sustainability Programme project No. LO1303 (MSMT-7778/2014) and also by the European Regional Development Fund under the project CEBIATech No. CZ.1.05/2.1.00/03.0089.

\section{References}

1. G. Harih, B. Dolšak, Int J Ind Ergonom, 43, 288 (2013)

2. A.G. González, J. G. Sanz-Calcedo, O. López, D.R. Salgado, I. Cambero, J. M. Herrera, Procedia Eng. 132, 1014 (2015)

3. M. Patkin, HFESA, 15 (2001)

4. K. A. Grant, D. J. Habes, L. L. Steward, , Int J Iind Ergonom, 10, 199 (1992)

5. Y. Kong, B. D. Lowe, Int J Iin Ergonom, 35, 495, (2005)

6. R. G. Dong, J. Z. Wu, D. E. Welcome, T. W. McDowell, Med Eng Pphys, 30, (2008)

7. B. Wimer, R. G. Dong, D. E. Welcome, Ch. Warren, T.W. McDowell, Med Eng Phys, 31, 695 (2009)

8. M. Motamedzade, A. Choobineh, M. A. Mououdi, S. Arghami, Int J Int Ergonom, 37, 581 (2007)

9. I. Dianat, M. Nedaei, M. A. M. Nezami, Int J Int Ergonom, 45, 13 (2015)

10. J. Dobránsky, L. Běhálek, Key Eng Mat, 669, 95 (2016) 